Check for updates

Cite this: RSC Adv., 2017, 7, 37923

Received 15th June 2017 Accepted 18th July 2017

DOI: $10.1039 / \mathrm{c} 7 \mathrm{ra06680e}$

rsc.li/rsc-advances

\title{
Agricultural waste-derived activated carbon for high performance lithium-ion capacitors
}

\author{
Bing Li, (D) ab Hongyou Zhang, ${ }^{\text {ab }}$ Dabin Wang, ${ }^{\text {ab }}$ Hong Lv ${ }^{\star a b}$ and Cunman Zhang ${ }^{\star a b}$
}

Activated carbon (AC) derived from the most common agricultural waste, corncob, has been synthesized through a simple chemical activation process. Furthermore, high energy density lithium-ion capacitors (LICs) were fabricated using corncob-derived $\mathrm{AC}$ as the cathode and commercially available $\mathrm{Li}_{4} \mathrm{Ti}_{5} \mathrm{O}_{12}$ as the anode. The optimized LIC achieves a maximum energy density of $79.6 \mathrm{~W} \mathrm{~h} \mathrm{~kg}^{-1}$ and is also capable of delivering high power density of $4 \mathrm{~kW} \mathrm{~kg}^{-1}$, which is much higher than that of similar constructions employing commercial AC as the cathode. In addition, the corncob-based LIC exhibits great cycle performance with $85.2 \%$ retention of the initial capacitance value after 2000 cycles. The present research offers a new approach for the development of high performance LICs employing carbonaceous electrodes of biomass precursors. These results make the corncob-derived activated carbon the most promising candidate for future energy storage applications.

\section{Introduction}

With the booming development of the advanced energy storage market, urgent demands have been proposed to meet the increased requirements of future applications, ranging from portable electronic devices to uninterrupted power systems (UPS) and hybrid electric vehicles (HEV). Supercapacitors (also termed as SCs) and lithium-ion batteries (LIBs) are currently recognized as the two promising energy storage solutions for future applications. Technically, the energy densities of LIBs can reach up to $180 \mathrm{~W} \mathrm{~h} \mathrm{~kg}^{-1}$. Although LIBs has a low power density, they have found their place in most situations where power performance gives way to energy characteristics. Although SC has a low energy density (less than $10 \mathrm{~W} \mathrm{~h} \mathrm{~kg}^{-1}$ ), it can offer much higher power density (about $10 \mathrm{~kW} \mathrm{~kg}^{-1}$ ) than batteries. ${ }^{1}$ It is widely believed that supercapacitors will play an important role and can, if not fully replace, supplement batteries in the energy storage field.

However, many obstacles remain to be tackled before the large-scale applications of SCs can be envisaged. Above all, improving the energy density of SCs is a task of top priority. LICs combining a battery-type electrode and a capacitor-type electrode are considered to be the most promising route to achieve the abovementioned goal. Normally, LICs demonstrate the integrated advantages of both SCs and LIBs; this means that they can deliver higher energy density than SCs and higher power density than LIBs. LICs bridge the gap between SCs and

${ }^{a}$ Clean Energy Automotive Engineering Center, Tongji University, Shanghai 201804, China. E-mail: zhangcunman@tongji.edu.cn; lvhong@tongji.edu.cn; Fax: +86 21 69589355; Tel: +862169589355

${ }^{b}$ School of Automotive Studies, Tongji University, Shanghai 201804, China
LIBs and they have been given widespread attention since the concept was first proposed by Amatucci et al. in 2001, who employed nanostructured $\mathrm{Li}_{4} \mathrm{Ti}_{5} \mathrm{O}_{12}$ (LTO) as the anode and AC as the cathode, and the LICs offered an energy density of over 20 $\mathrm{W} \mathrm{h} \mathrm{kg}{ }^{-1}$. $^{2}$ Since then, several Li-insertion materials have been proposed for LICs, but LTO remains the most promising candidate due to its outstanding properties such as zero-strain insertion, no solid electrolyte interface (SEI) formation, lowcost, and safety. Considering that research on battery-like electrode materials has made great progress, there is pressing need to explore applicable carbonaceous materials to ensure the high power density of LICs.

High-performance electrode materials that can be easily mass-produced are the prerequisites for supercapacitors to be widely accepted by the market. In the last decade, carbon-based materials from AC to CNTs have been widely investigated as electrode materials for application in electrochemical supercapacitors. ${ }^{3,4}$ Recently, R. Gokhale et al. ${ }^{5}$ used oligomer-salt as a precursor to prepare porous carbon as an electrode material for LICs, and many other researchers ${ }^{6,7}$ synthesized various carbon materials by adopting different kinds of polymers. However, most activated carbons derived from various sources including biomass and organic polymers demonstrate relatively low capacity $\left(\sim 50 \mathrm{~mA} \mathrm{~h} \mathrm{~g}{ }^{-1}\right)$ in non-aqueous electrolytes..$^{8-10}$ However, most of the researches on carbon derived from polymers involves expensive polymers and the tedious processes are usually detrimental to health. Practically, these low-capacity carbonaceous materials show little potential for commercialization.

Recently, several studies have reported graphene-based materials that have been employed as a cathode along with the LTO anode, and the LICs prepared using them achieved 
high energy densities of over $40 \mathrm{~W} \mathrm{~h} \mathrm{~kg}{ }^{-1} \cdot{ }^{\mathbf{1 1 , 1 2}}$ However, the scalability, reproducibility, and high-cost would hold back graphene-based materials from commercialization. Therefore, because of their easy accessibility, low-cost, good chemical stability, and non-toxicity, high surface area porous carbons derived from bio-waste have attracted significant attention. For example, Sennu et al. ${ }^{13}$ used Prosopis juliflora-derived activated carbon as a cathode to fabricate the high-energy LIC with a maximum energy density of $\sim 80 \mathrm{~W} \mathrm{~h} \mathrm{~kg}^{-1}$ with $76 \%$ retention after 10000 cycles. Agricultural waste-derived AC tends to have rich surface functional groups, enhancing the capacity. ${ }^{\mathbf{1 4 , 1 5}}$ Moreover, these kinds of activated carbons demonstrate a wide range of pore size distribution, which enables more active sites for charge accumulation.

In this study, we first demonstrated the large surface area AC with high capacity derived from corncob through simple steps of pyrolysis and activation at high temperatures for the LIC application. More specifically, with the corncob-derived activated carbon (AC) applied as the cathode in LIC assembly along with commercially available spinel phase $\mathrm{Li}_{4} \mathrm{Ti}_{5} \mathrm{O}_{12}$ as the anode, the as-obtained AC is competitive in future energy storage applications.

\section{Experimental}

\subsection{Preparation of $\mathrm{AC}$}

AC was prepared first by carbonization followed by activation of the most common agricultural waste - corncobs. Corncob powders were obtained from Chifeng, Inner Mongolia, China. Subsequently, the product was chemically activated by $\mathrm{KOH}$ as the activating agent at $850{ }^{\circ} \mathrm{C}$ for $3 \mathrm{~h}$. The detailed processes are reported in our previous study. ${ }^{\mathbf{1 6}}$ There was an additional ball milling process after activation. The obtained finer powders were used for the electrode fabrication.

\subsection{Characterization}

Electron microscopy (TEM) and scanning electron microscopy (SEM) were employed to determine the morphologies and texture of the activated carbon. The elemental contents and surface functional groups were determined by elemental analysis, Fourier transform infrared (FT-IR) spectroscopy, and X-ray photoelectron spectroscopy (XPS). A Micromeritics ASAP 2020 sorptometer was used to analyze the microstructure of the samples.

\subsection{Electrochemical measurements}

The working electrode was fabricated by mixing the as-prepared AC with Super-P carbon black and polyvinylidene fluoride (PVDF) $(8: 1: 1)$ in $N$-methyl-2-pyrrolidone (NMP) to form a homogeneous slurry, which was then coated onto the aluminum foil (cathode) and copper foil (anode). The electrodes were separated by glass microfiber filters (Whatman GF/C) soaked with electrolyte. For the half-cell measurements, we used metallic lithium as the reference and counter electrode. In the LIC, AC was used as the cathode and commercially available $\mathrm{Li}_{4} \mathrm{Ti}_{5} \mathrm{O}_{12}$ (MTI Corporation, Shenzhen, China) was used as the anode in $1 \mathrm{M} \mathrm{LiPF}_{6}$ in ethylene carbonate, diethyl carbonate, and dimethyl carbonate (EC : DEC : DMC = 1:1:1 by vol).

Cyclic voltammetry (CV) was carried out at a scan rate ranging from 5 to $100 \mathrm{mV} \mathrm{s}^{-1}$. Galvanostatic charge/discharge cycling (GCD) was conducted in the current density range from 0.1 to $2 \mathrm{~A} \mathrm{~g}^{-1}$. Electrochemical impedance spectroscopy (EIS) was tested in the frequency range from $0.1 \mathrm{~Hz}$ to $100 \mathrm{kHz}$ with a potential amplitude of $10 \mathrm{mV}$. All the tests were performed using a CHI 760E electrochemical workstation. Cycling performances were determined using a LAND battery tester (Wuhan Jinnuo Electronics Co., Ltd) under ambient temperature conditions.

\section{Results and discussion}

Fig. 1 shows the SEM and TEM images of the corncob-based AC. The sample comprises a large density of interconnected micropores as well as macropores. The $\mathrm{N}_{2}$ sorption-desorption isotherms and pore size distributions (PSDs) of the corncobbased AC are schematically shown in Fig. 2. Apparently, mesopores/macropores can facilitate mass transport and thereby ensure the power performance of the capacitors. ${ }^{17-20}$ Moreover, the existence of ample micropores could effectively increase the active sites for charge storage. The BET specific surface area of corncob-based AC obtained from $\mathrm{N}_{2}$ sorptiondesorption isotherms was found to be $\sim 2646 \mathrm{~m}^{2} \mathrm{~g}^{-1}$, which confirmed the existence of abundant micropores. The micropore volume is $1.50 \mathrm{~cm}^{3} \mathrm{~g}^{-1}$, as determined from the figure of the PSDs.

FT-IR spectroscopy (Fig. 3a) an XPS (Fig. 3b) were employed to evaluate the surface chemistry properties of the as-prepared AC. Basically, the FT-IR spectrum displays two main bands located at $1545 \mathrm{~cm}^{-1}$ and 1060-1095 $\mathrm{cm}^{-1}$, which may have resulted from highly conjugated $\mathrm{C}-\mathrm{O}$ in a quinone/carbonyl structure $^{21}$ and the $\mathrm{C}-\mathrm{O}$ stretching vibration of various functionalities, ${ }^{22,23}$ respectively. Based on the XPS spectra, we can easily draw a conclusion that the AC derived from corncob is rich in quinone/carbonyl groups, which can further improve the
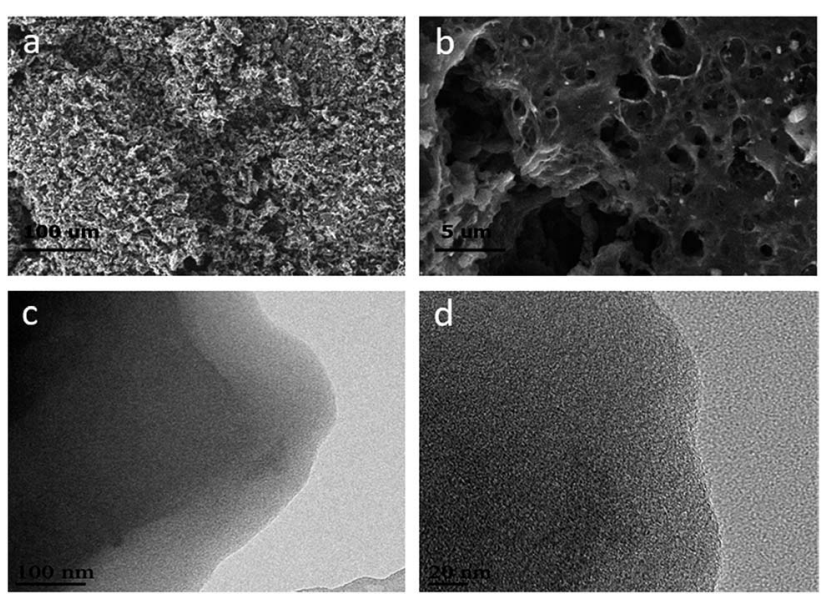

Fig. 1 Typical ( $a$ and b) SEM and ( $c$ and d) TEM images of the corncobbased activated carbon. 

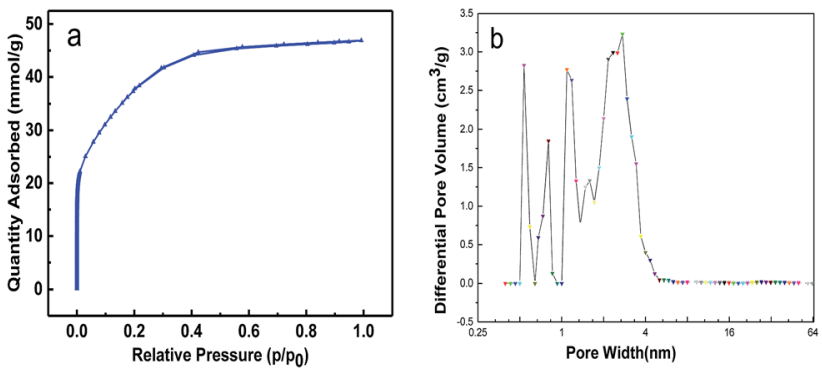

Fig. 2 (a) $\mathrm{N}_{2}$ sorption-desorption isotherms of the corncob-based activated carbon at $77 \mathrm{~K}$; (b) pore-size distribution of the corncobbased activated carbon.

wettability of the carbon surface and reduce the charge transfer resistance and will finally contribute to the improvement of the electrochemical performance of the AC electrode. ${ }^{24}$

To determine the mass loading of each electrode in the LIC assembly, it is essential to evaluate the single-electrode performance along with metallic lithium in half-cell configurations. Considering the decomposition potential of the electrolyte, the $\mathrm{AC}$ cathode was tested in a half cell from $3 \mathrm{~V}$ to $4.6 \mathrm{~V}$ vs. $\mathrm{Li}$ (current density ranging from $100 \mathrm{~mA} \mathrm{~g}^{-1}$ to $1000 \mathrm{~mA} \mathrm{~g}^{-1}$ ), and the corresponding results are presented in Fig. 4 . The sample shows a linear increase in potential with time; this clearly suggests the perfect desorption/adsorption process of $\mathrm{PF}_{6}{ }^{-}$ anions and the formation of an electrostatic double layer across the electrolyte/electrode interface. The profiles show the typical characteristic of capacitors and reveal an initial discharge capacity of $75.9 \mathrm{~mA} \mathrm{~h} \mathrm{~g}^{-1}$ at $100 \mathrm{~mA} \mathrm{~g}^{-1}$, and the $91.7 \%$ capacity is retained after 1000 cycles. In the same voltage range, this value is much higher than that previously reported for various activated carbons. ${ }^{8,25,26}$ Detailed data were obtained and compared with the as-obtained results in Table 1; the half-cell performance of the commercially available LTO under the same testing conditions is also given in Fig. 4.

Based on the half-cell performance of the activated carbon, the optimized mass ratio of AC to LTO was about $2: 1$. However, during the course of the experiment, mass loading was indirectly controlled by altering the thickness of the electrode coating. Thus, it was unpractical to accurately determine the mass loading of the electrodes with materials that have
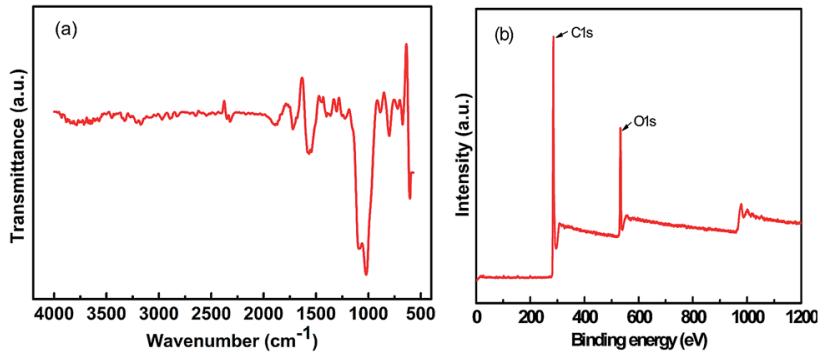

Fig. 3 (a) FT-IR and (b) XPS spectra of the corncob-based activated carbon.
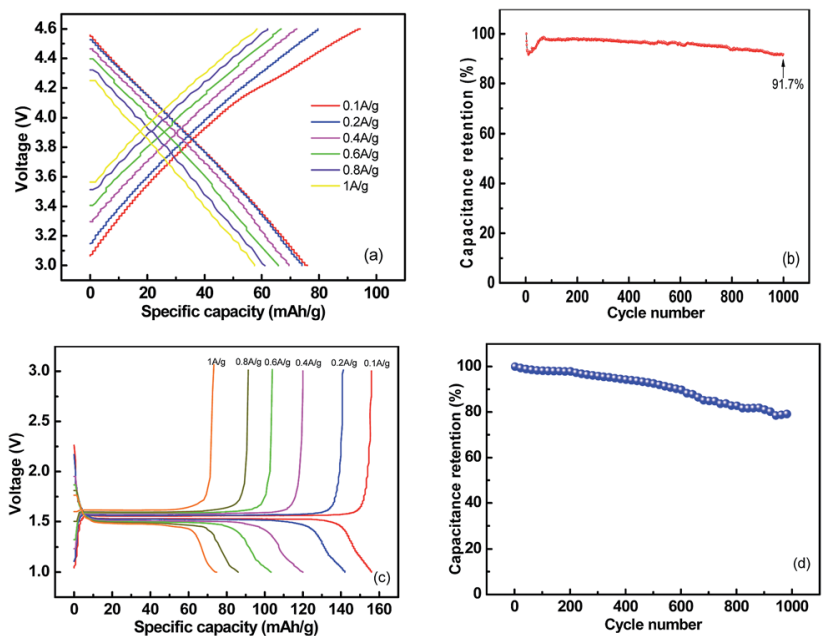

Fig. 4 (a) Galvanostatic charge/discharge curves of corncob-based activated carbon in the half-cell between 3 and $4.6 \mathrm{~V}$ vs. Li with current density ranging from $100 \mathrm{~mA} \mathrm{~g}^{-1}$ to $1000 \mathrm{~mA} \mathrm{~g}^{-1}$, in which metallic lithium acts as both counter and reference electrode; (b) plot of cycle performance of AC//Li half-cell; (c) GCD curves of LTO in the half-cell between 1 and $3 \mathrm{~V}$ vs. Li at various current densities in which metallic lithium acts as both counter and reference electrode; (d) plot of cycle performance of LTO//Li half-cell.

different mass densities. To obtain the optimum electrode matching, a series of LICs with the thickness ratio of AC to LTO ranging from $1: 1$ to $4: 1$ (thickness ratios were converted to the corresponding mass ratios of AC to LTO in the following explanations) were fabricated and tested between 1 and $3 \mathrm{~V}$ under various conditions. The GCD curves at a current density of $100 \mathrm{~mA} \mathrm{~g}^{-1}$ (in the case of the full-cell, all the current density values are based on the total mass of the active material of both electrodes) and cyclic voltammetry curves at a sweep rate of $5 \mathrm{mV} \mathrm{s}^{-1}$ of the LICs are profiled in Fig. $5 \mathrm{a}$ and b, respectively. The results show that the LIC with AC to LTO mass ratio of $1.5: 1$ displays the greatest performance; considering the experimental limitations and the dissimilarity between full-cell and half-cell performance, the result is in accordance with the anticipated value based on the half-cell performance within experimental error. Fig. $5 \mathrm{c}$ represents the GCD curves at various current densities of the optimized LIC (AC : LTO $=1.5: 1$ ). The curves are neither linear like those of capacitors nor inflected like those of batteries; this is attributed to the integrated reaction mechanism of the LICs. Briefly, during the charge process, lithium ions intercalated into the lattice of LTO (faradaic reaction) along with the $\mathrm{PF}_{6}{ }^{-}$anions simultaneously accumulated on the interface of the electrolyte/electrode (non-faradaic reaction), ${ }^{2,27}$ and the reaction was completely reversed in the discharge process. Thus, the synergistic effects of both capacitors and batteries are demonstrated by the GCD curves. This can also be validated from the $\mathrm{CV}$ profiles displayed in Fig. $5 \mathrm{~d}$. A combination of $\mathrm{CV}$ characteristics of both AC and LTO in the half-cell configurations in Fig. 6 and sharp increase/decrease in current response are observed at the critical point of $\sim 1.5 \mathrm{~V}$ at low sweep rate, which indicates that the Li-insertion/deintercalation occurs at the anode during cycling and the 
Table 1 Typical half-cell capacity of carbonaceous materials based on a non-aqueous electrolyte

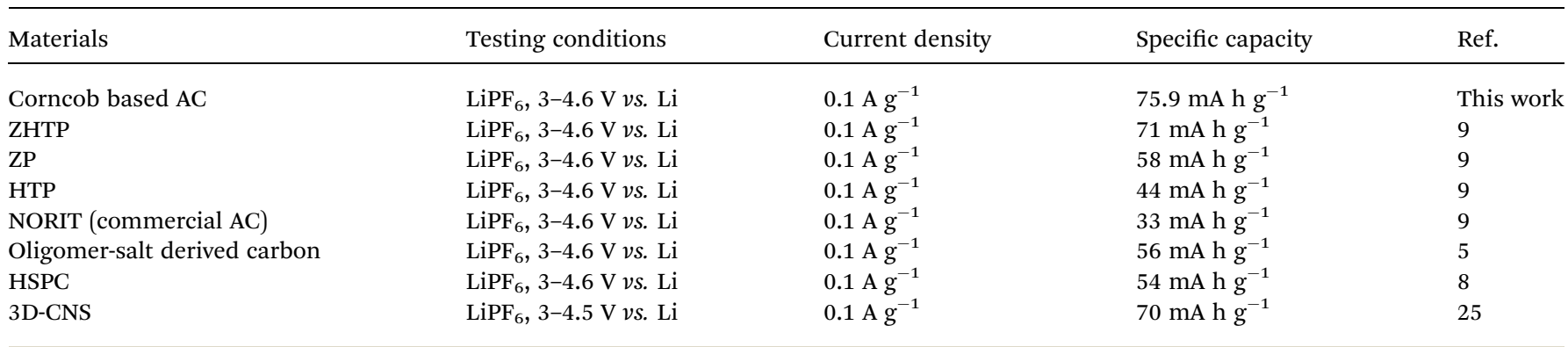
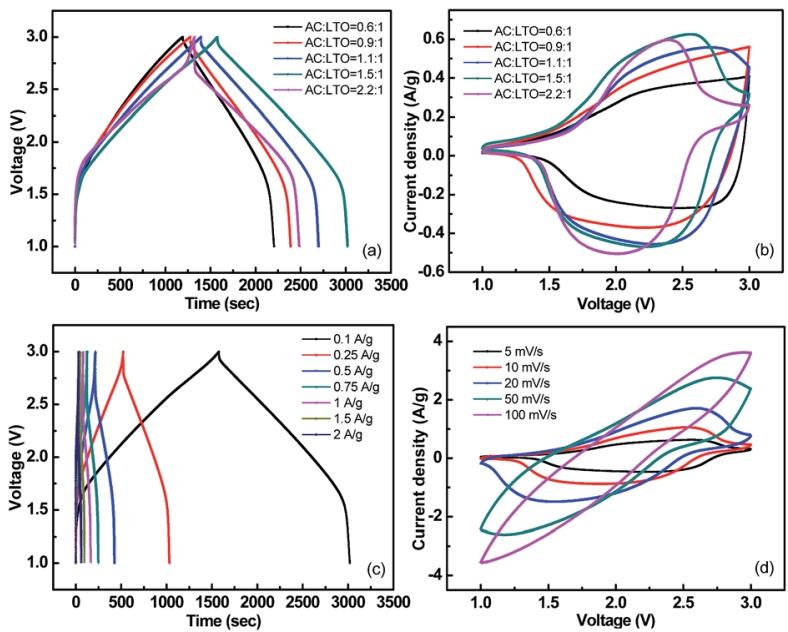

Fig. 5 (a) Galvanostatic charge/discharge curves at a current density of $100 \mathrm{~mA} \mathrm{~g}^{-1}$ and (b) cyclic voltammetry curves at a sweep rate of $5 \mathrm{mV} \mathrm{s}^{-1}$ of Li-HECs comprising corncob derived carbons as the cathode and spinel phase $\mathrm{Li}_{4} \mathrm{Ti}_{5} \mathrm{O}_{12}$ as the anode with different cathode to anode mass ratio ranging from $0.6: 1$ to $2.2: 1$; (c) galvanostatic charge/discharge curves; and (d) cyclic voltammetry curves of the typical Li-HEC (AC : LTO = $1.5: 1$ ).

corresponding formation of an electric double layer across the AC electrolyte/electrode interface. ${ }^{10}$ In addition, the curves at high sweep rate exhibit severe distortion, which results from the polarization of the electrodes, and the faradaic reaction limits the charge storage/release rate under high power conditions.

The Ragone plot was obtained from galvanostatic charge/ discharge measurements of the as-fabricated AC//LTO LICs along with those reported for similar constructions involving
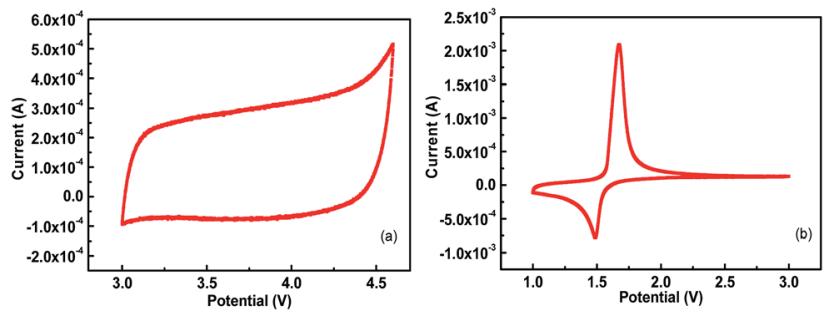

Fig. 6 (a) CV curves of $A C$ in the half-cell between 3 and $4.6 \mathrm{~V}$ vs. Li at a sweep rate of $1 \mathrm{mV} \mathrm{s}^{-1}$, (b) CV curves of LTO in the half-cell between 1 and $3 \vee v s$. Li at a sweep rate of $1 \mathrm{mV} \mathrm{s}^{-1}$. carbonaceous material as the cathode and pure LTO as the anode (Fig. 7a and b). The specific power and energy densities were calculated using the following relations: $P=(U \times i / m)$ and $E=(P \times t)$, where $U=\left(U_{\max }+U_{\min }\right) / 2, U_{\max }$ and $U_{\min }$ are the potentials at the beginning and end of discharge curves, respectively, and $m$ is the total active mass of both electrodes. $^{25,27,28}$ The corncob-derived activated carbon-based LICs delivered the highest energy density of $79.6 \mathrm{~W} \mathrm{~h} \mathrm{~kg}^{-1}$, which was much higher (2 times) than that of a similar commercial activated carbon-based system $\left(\sim 36 \mathrm{~W} \mathrm{~h} \mathrm{~kg}{ }^{-1}\right) .{ }^{10}$ The optimized AC//LTO LIC delivered an excellent performance even at high power density ( $32.7 \mathrm{~W} \mathrm{~h} \mathrm{~kg}^{-1}$ at $\left.4 \mathrm{~kW} \mathrm{~kg}^{-1}\right)$. It is worth noting that our device outperformed most of the similar constructions involving carbonaceous materials as the cathode and LTO as the anode, as well as some other constructions, for instance, AC// carbon-coated- $\mathrm{Li}_{4} \mathrm{Ti}_{5} \mathrm{O}_{12}\left(35.5 \mathrm{~W} \mathrm{~h} \mathrm{~kg}^{-1}\right)$ reported by H.-G. Jung et al., ${ }^{29} \mathrm{AC} / /$ nano-crystalline $\mathrm{Li}_{4} \mathrm{Ti}_{5} \mathrm{O}_{12} / \mathrm{CNF}\left(55 \mathrm{~W} \mathrm{~h} \mathrm{~kg}^{-1}\right)$ reported by K. Naoi et al., ${ }^{30}$ poly(acrylamide-co-acrylic acid) potassium salt-derived carbon// $/ \mathrm{Li}_{4} \mathrm{Ti}_{5} \mathrm{O}_{12}\left(55 \mathrm{~W} \mathrm{~h} \mathrm{~kg}^{-1}\right)$ reported by D. Puthusseri et al., ${ }^{10}$ coconut-derived activated carbon// $\mathrm{Li}_{4} \mathrm{Ti}_{5} \mathrm{O}_{12}\left(69 \mathrm{~W} \mathrm{~h} \mathrm{~kg}{ }^{-1}\right)$ reported by A. Jain et al., ${ }^{8} \mathrm{AC} / / \mathrm{Li}_{4} \mathrm{Ti}_{5} \mathrm{O}_{12}$ spheres $\left(74.3 \mathrm{~W} \mathrm{~h} \mathrm{~kg}^{-1}\right)$ reported by S.-X. Deng et al. ${ }^{31}$ and the LICs of $\mathrm{AC} / \mathrm{TiO}_{2}$ (B) reported by Aravindan et al..$^{32}$ Moreover, the corncob-based AC//LTO hybrid system is only rivaled by similar graphene-based structures, ${ }^{9}$ but the introduction of graphene results in much higher cost than that of the biomass-derived carbons employed herein. Thus, the combination of low-cost agricultural waste-derived activated carbon and commercially available $\mathrm{Li}_{4} \mathrm{Ti}_{5} \mathrm{O}_{12}$ would make the biomass-derived carbons have great potential for large scale stationary and automotive applications.
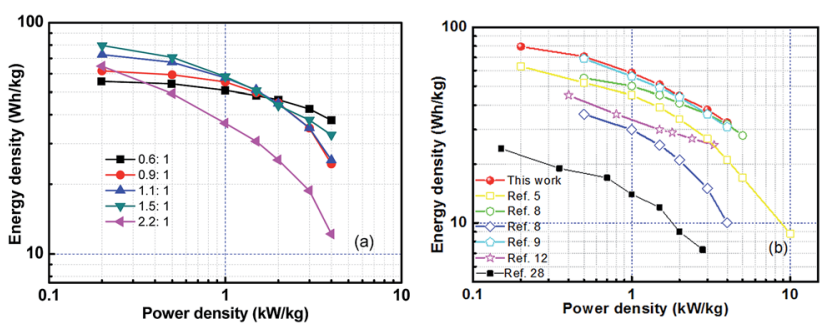

Fig. 7 (a) Ragone plot of the as-fabricated Li-HECs and (b) comparison with those reported for similar constructions involving carbonaceous material as the cathode and pure LTO as the anode. 


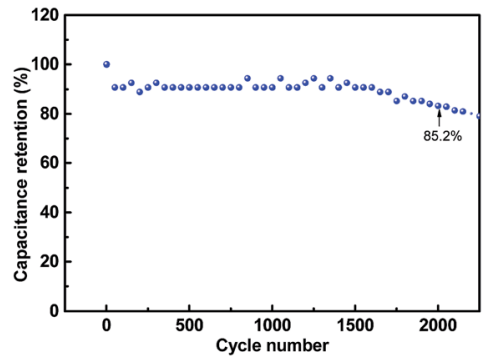

Fig. 8 Cycling performance of the corncob-based AC//LTO Li-HEC at a current density of $2 \mathrm{~A} \mathrm{~g}^{-1}$. The data points were obtained every 50 cycles.

Cycle life is of great significance for practical applications, and hence, the cycling profiles of the as-obtained AC//LTO LIC were determined at a current density of $2 \mathrm{~A} \mathrm{~g}^{-1}$. As depicted in Fig. 8, the corncob-based AC//LTO LIC retained $85.2 \%$ of the original value after 2000 cycles. After 2251 cycles, it reached $79.01 \%$ of the original value. These results are tolerable considering that the lithium ion batteries often last for less than 1000 cycles. Moreover, the acceptable attenuation mainly originated from the intrinsic nature of the commercially available $\mathrm{Li}_{4} \mathrm{Ti}_{5} \mathrm{O}_{12}{ }^{10}$ This issue can be alleviated through various approaches such as carbon coating ${ }^{29}$ or integrating LTO with other materials such as graphene ${ }^{9}$ and carbon nano-fibers. ${ }^{30}$

\section{Conclusion}

In summary, high-energy density LIC was constructed with corncob-derived $\mathrm{AC}$ as the cathode and commercial $\mathrm{Li}_{4} \mathrm{Ti}_{5} \mathrm{O}_{12}$ as the anode. The optimized LIC delivered a maximum energy density of $79.6 \mathrm{~W} \mathrm{~h} \mathrm{~kg}^{-1}$ at $200 \mathrm{~W} \mathrm{~kg}^{-1}$, which was much higher than that of commercial activated carbon-based configurations and similar constructions employing carbonaceous materials as the cathode and LTO as the anode. The corncob-based LIC was also capable of delivering high power density of $4 \mathrm{~kW} \mathrm{~kg}^{-1}$, which is twice that of the lithium-ion rechargeable batteries $(<2$ $\mathrm{kW} \mathrm{kg}{ }^{-1}$ ). This study offers a new approach for the exploitation of high-surface area porous carbons derived from agricultural wastes for constructing LICs with high energy density. Furthermore, the results make corncob-derived activated carbon the most promising candidate for future energy storage applications.

\section{Acknowledgements}

The authors appreciate the National Natural Science Foundation (No. 21676204) and Program for Young Excellent Talents in Tongji University.

\section{References}

1 P. Simon and Y. Gogotsi, Nat. Mater., 2008, 7, 845-854.

2 G. G. Amatucci, F. Badway, A. D. Pasquier and Z. Tao, J. Electrochem. Soc., 2001, 148, A930-A939.
3 A. G. Pandolfo and A. F. Hollenkamp, J. Power Sources, 2006, 157, 11-27.

4 R. A. Fisher, M. R. Watt and W. J. Ready, ECS J. Solid State Sci. Technol., 2013, 2, M3170-M3177.

5 R. Gokhale, V. Aravindan, P. Yadav, S. Jain, D. Phase, S. Madhavi and S. Ogale, Carbon, 2014, 80, 462-471.

6 P. Yadav, A. Banerjee, S. Unni, J. Jog, S. Kurungot and S. Ogale, Chemsuschem, 2012, 5, 2159-2164.

7 M. Zhong, E. K. Kim, J. P. Mcgann, S. E. Chun, J. F. Whitacre, M. Jaroniec, K. Matyjaszewski and T. Kowalewski, J. Am. Chem. Soc., 2015, 134, 14846.

8 A. Jain, V. Aravindan, S. Jayaraman, P. S. Kumar, R. Balasubramanian, S. Ramakrishna, S. Madhavi and M. P. Srinivasan, Sci. Rep., 2013, 3, 3002.

9 K. Leng, F. Zhang, L. Zhang, T. Zhang, Y. Wu, Y. Lu, Y. Huang and Y. Chen, Nano Res., 2013, 6, 581-592.

10 D. Puthusseri, V. Aravindan, S. Madhavi and S. Ogale, Electrochim. Acta, 2014, 130, 766-770.

11 M. D. Stoller, S. Murali, N. Quarles, Y. Zhu, J. R. Potts, X. Zhu, H.-W. Ha and R. S. Ruoff, Phys. Chem. Chem. Phys., 2012, 14, 3388-3391.

12 V. Aravindan, D. Mhamane, W. C. Ling, S. Ogale and S. Madhavi, ChemSusChem, 2013, 6, 2240-2244.

13 P. Sennu, H. J. Choi, S. G. Baek, V. Aravindan and Y. S. Lee, Carbon, 2016, 98, 58-66.

14 A. Elmouwahidi, Z. Zapata-Benabithe, F. Carrasco-Marín and C. Moreno-Castilla, Bioresour. Technol., 2012, 111, 185190.

15 L. Jiang, J. Yan, L. Hao, R. Xue, G. Sun and B. Yi, Carbon, 2013, 56, 146-154.

16 C. Zhang, Z. Geng, M. Cai, J. Zhang, X. Liu, H. Xin and J. Ma, Int. J. Hydrogen Energy, 2013, 38, 9243-9250.

17 B. Fang, J. H. Kim, M. S. Kim, A. Bonakdarpour, A. Lam, D. P. Wilkinson and J. S. Yu, J. Mater. Chem., 2012, 22, 19031-19038.

18 B. Fang, J. H. Kim, M. S. Kim and J. S. Yu, Acc. Chem. Res., 2013, 46, 1397.

19 B. Fang, A. Bonakdarpour, M. S. Kim, J. H. Kim, D. P. Wilkinson and J. S. Yu, Microporous Mesoporous Mater., 2013, 182, 1-7.

20 S. Q. Fan, B. Fang, J. H. Kim, B. Jeong, C. Kim, J. S. Yu and J. Ko, Langmuir, 2010, 26, 13644.

21 C. Namasivayam and D. Kavitha, Microchem. J., 2006, 82, 4348.

22 I. A. Schepetkin, A. I. Khlebnikov, S. Y. Ah, S. B. Woo, C. S. Jeong, O. N. Klubachuk and B. S. Kwon, J. Agric. Food Chem., 2003, 51, 5245.

23 A. El-Hendawy, Appl. Surf. Sci., 2005, 252, 287-295.

24 L. I. Li-Xiang and L. I. Feng, New Carbon Mater., 2011, 26, 224-228.

25 V. Aravindan, W. Chuiling, M. Reddy, G. S. Rao, B. V. Chowdari and S. Madhavi, Phys. Chem. Chem. Phys., 2012, 14, 5808-5814.

26 H. Kim, M. Y. Cho, M. H. Kim, K. Y. Park, H. Gwon, Y. Lee, K. C. Roh and K. Kang, Adv. Energy Mater., 2013, 3, 15001506. 
27 V. Aravindan, N. Shubha, W. C. Ling and S. Madhavi, J. Mater. Chem. A, 2013, 1, 6145-6151.

28 V. Aravindan, W. Chuiling and S. Madhavi, J. Mater. Chem., 2012, 22, 16026-16031.

29 H. G. Jung, N. Venugopal, B. Scrosati and Y. K. Sun, J. Power Sources, 2013, 221, 266-271.
30 K. Naoi, S. Ishimoto, Y. Isobe and S. Aoyagi, J. Power Sources, 2010, 195, 6250-6254.

31 S. X. Deng, J. W. Li, S. B. Sun, H. Wang, J. B. Liu and H. Yan, Electrochim. Acta, 2014, 146, 37-43.

32 V. Aravindan, N. Shubha, W. C. Ling and S. Madhavi, J. Mater. Chem. A, 2013, 1, 6145-6151. 